\title{
Influence of Household and Area Characteristics on the Residential Mobility of Households
}

\author{
TAPANI VALKONEN \\ Professor \\ Department of Sociology \\ University of Helsinki \\ TUIJA MARTELIN \\ Research Associate \\ Department of Sociology \\ University of Helsinki
}

Short-distance moves are much more common than long-distance moves, which have conventionally been the main topic of demographic migration research. For example, there are annually about 100000 moves within the Helsinki metropolitan area, whereas there are less than 40000 moves in and out of this area. Intra-urban mobility strongly influences population development in sub-areas of cities, and knowledge of this phenomenon is needed to improve population projections used for planning purposes. Residential mobility is important also from the point of view of housing policy.

The purpose of this paper is to analyze the relationships between the residential (or intra-urban) mobility of households and variables describing the households and the residential areas where the households are located. The paper is based on data from a more comprehensive study on migration and residential mobility in the Helsinki metropolitan area (Valkonen, Martelin and Summa, 1984).

\section{Conceptual issues and hypotheses on factors affecting the probability of moving}

Geographic mobility is conceptually a more complicated phenomenon than, for example, mortality or fertility, because quite different types of events may be counted as moves. In this article, only a specific type of move is analyzed, namely the voluntary moves of whole households within a local labor market area. This type of moves has the following characteristics:

1. The move takes place within a local labor-market area. These short-distance moves are counted as residential mobility, whereas migration proper is considered to involve a shift from one local labor market area to another and hence ordinarily involves employment considerations. Residential mobility includes shifts that could take place without changes in employment.

2. The unit moving is a whole household and the composition of the household does not change in connection with the move. Moves generated by formation or dissolution of households or other events of that sort are excluded.

3. Moving is voluntary and not precipitated, for example, by eviction.

The analysis is based on the assumption that the decision to move from a dwelling and the decision to select an alternative dwelling are separate processes and these two stages can be studied separately (see e.g. Brown and Moore, 1970, 2). This paper 
deals only with the first stage of the moving process and analyzes factors affecting the probabilities of moving.

Earlier studies have shown (see e.g. Rossi, 1980 and Summa, 1984) that the phase of the life cycle of the household, type of tenure of the dwelling and the discrepancy between the housing needs and the housing situation of the household are among the most important factors influencing residential mobility. Empirical results on the significance of the income level of the households and other socioeconomic variables are inconsistent (Summa, 1984, 13-16), but this may have been caused by difficulties in controlling the effects of other variables. It seems logical to assume that households with higher income have better opportunities to move and more probably do move than lower income households, if the households are similar in other aspects.

The empirical part of this paper attempts to test and elaborate earlier results on the influence of the phase of the household life cycle, discrepancy between housing needs and housing situation and household income. The effect of the tenure type will not be studied, since the data analyzed in this paper are restricted to owner-occupants.

In addition to the analysis of the influence of household characteristics on the probability of moving, the study attempts to analyze whether the characteristics of the residential areas of the households also influence the probability of moving either directly or by modifying the effect of household characteristics. Intuitively it seems likely that area characteristics affect the decision to move or not to move. The basic hypothesis is that households attempt to leave areas not suitable for them and this causes extra mobility in addition to "the normal mobility» determined by household characteristics. Two properties of the residential areas, namely the percentage of highincome households and the percentage of dwellings in high-rise buildings in the area, will be used in this analysis.

\section{Data}

The original data of the more comprehensive study consisted of two parts: a) individual level records on socio-demographic and housing characteristics of the inhabitants of the Helsinki metropolitan area from the 1980 census ( 751500 persons) and b) records on all persons who moved from or to the Helsinki area or moved within the area in 1981 (132 900 persons). The records on moves were linked with the census records by means of personal identification numbers to obtain data on the socio-demographic and housing variables of the movers who lived in the Helsin$\mathrm{ki}$ area at the time of the census (November 1st 1980) ${ }^{1}$. The linkage was quite successful and only 6.2 percent of the movers from or within the Helsinki area were not identified in the census records. Most of the unidentified movers were either babies born after the census or young people who had moved to the region after the census. Movers who could not be identified in the census are not included in this analysis.

Since information on exactly the same variables is available both for the movers and the population exposed to the risk of moving, it is possible to calculate probabilities of moving for any subgroup of population that can be defined by using census variables.

The Helsinki metropolitan area means in this study the cities of Helsinki (pop. 483 100), Espoo (pop. 141300 ) and Vantaa (pop. 134 000). The city of Kauniainen (pop. 7400 ) could not be included in the study because of lack of data on movers. The four cities mentioned above are commonly considered to belong to the same local labor market area, which even extends to some extent to neighboring areas. The moves analyzed here are moves within or between the cities of Helsinki, Espoo and Vantaa. Persons who moved from the Helsinki area during 1981 were excluded

1 The permission (TK 53-49-82) to use the census records was granted by the Central Statistical Office on May 26th, 1982. 
from the risk population. Of the movers within the Helsinki area 5.5 percent had moved more than once in 1981 . Only the first move of these persons was taken into account.

The data on movers included identification codes for the dwellings of destination. This made it possible to separate the moves where all the members of a household moved together from the moves of individual members of households. A household was classified as having moved intact if all members of the household had left the original dwelling and moved to the same dwelling of destination. This procedure is not quite appropriate to identify moves with no change in household composition, since it was not possible to know if there already were inhabitants in the dwelling of destination or if another person or other persons also moved into it. Particularly, it is likely that many of the moves of one-person households are associated with changes in household composition (e.g. in connection with marriage or moving to a friend's apartment). To avoid the error involved, one-person households were excluded from the data for this paper.

Since the study is not based on survey data, it is not possible to distinguish between voluntary and involuntary moves. Taking into account the Finnish housing system, it is reasonable to assume that almost all moves from dwellings owned by the occupant are voluntary, whereas involuntary moves are more frequent in other sectors of the housing market. The main type of ownership of dwelling in the Helsinki area is the owning of an apartment in a housing share-holding company. Only households of this type (46 percent of all households) were included in the analysis, and all households living in rented or employer-owned dwellings as well as households not living in dwellings were excluded. In this way the type of tenure does not vary in the data, and its influence on mobility is not studied.

To avoid unnecessary complications some groups that were considered less central to the study were also excluded. Thus the final »risk population» included 61199 households (about 20 percent of the total number of households in the metropolitan area), which filled the following criteria:

- living in the cities of Helsinki, Vantaa or Espoo at the time of the census (November 1st, 1980) and not moving from this area in 1981,

- number of household members at least two, living in an apartment owned by the household,

- the age of the head of household from 25 to 59 years and

- the head of household economically active.

Of these households who could have moved, 4849 households or 7.9 percent moved to another dwelling in the Helsinki area in 1981. These moves will be analyzed in the empirical part of the paper.

\section{Variables and specific hypotheses}

The variables discussed in the general hypotheses are operationalized in the following way:

Phase of household life cycle: it is assumed that the probability of moving is higher than average for young households which are growing or anticipate growing. There are two variables measuring this factor:

a) The age of the head of household, which is classified into 5-year age-groups $(25-29,30-34, \ldots 55-59)$. It is assumed that the probability of moving decreases with the increasing age of the household head.

b) The type of household. The households are classified into three groups: 1. Families without children or households in which the head is not a member of a family.

2. Families with a child or children, all children younger than 7 years.

3. Families with children, at least one child at least 7 years old. 
It is assumed that probability of moving is highest in the second class, since the growth or anticipated growth of the family causes a need to adjust the housing situation to the new family composition.

Only one aspect of the discrepancy between housing needs and housing situation is taken into account, namely the difference between the number of rooms (kitchen included as a room) and the size of the household. Two classes are distinguished:

1. Densely living households: the difference between the number of rooms and the number of household members is zero or smaller. This implies, for example, that a three-member household has at most a kitchen, living room and one bedroom.

2. Less densely living households: the differences is one or more.

It is assumed that the probability of moving is higher for the more densely living households.

The economic resources of households are measured by the total taxable income of household members in 1979. It is assumed that the probability of moving for highincome households is greater than for low-income households. The household income is classified into three classes.

To analyze the possible influence of the area characteristics, the Helsinki area was divided into 141 residential areas. These were formed on the basis of statistical areas used by the municipalities. The average population of the residential areas is about 5000 inhabitants.

The following variables will be used in the analysis of the influence of area characteristics:

Percentage of high-income households in the areas could be computed from the census material of the study. The areas were divided into two classes:

1. High-income areas: the percentage of households earning 150000 FIM or more is at least 8 percent.

2. Low-income areas: other areas.

It is assumed that the »better» or high-income areas are, in general, preferred by households and there is less mobility in them than in the low-income areas. It is further assumed that the probability of moving for high-income households living in low-income residential areas is particularly high.

The physical character of the areas was measured by the percentage of dwellings in high-rise buildings. Three area types were distinguished:

1. Percentage of dwellings in high-rise buildings is more than 95 percent. Most of these areas are in the old and central parts of the city of Helsinki.

2. Percentage of dwellings in high-rise buildings is $85-95$ percent. Most of these areas are rather densely built suburbs.

3. Percentage of dwellings in high-rise buildings is less than 85 percent.

No hypotheses about the general effect of area type is made, but it is assumed that the mobility of young households and households with pre-school-age children is relatively higher in the compactly built central areas (type 1), where the opportunities for unattended outdoor play for children are worse than in other areas.

\section{Statistical method}

The annual probabilities of moving (at least once) for a sub-group of households were calculated as the ratio of the number of households who moved in 1981 to the total number of households in the sub-group in the risk population. All values of the variables, including the age of household head refer to the situation at the time of the census and not at the time of the move.

The importance of the household level variables and the contextual variables and their interactions as the determinants of the probability of moving was analyzed by a linear logistic model. The GLIM package was applied in fitting the model, assuming 
binomial error and using the logit link function, which means that the logit of the probability or $\log (\mathrm{p} /(\mathrm{l}-\mathrm{p}))$ is supposed to have a linear structure (Baker and Nelder, 1978).

First, a model with the household variables only was fitted. Only those interaction terms were included that appeared significant according to a test based on the $\chi^{2}$-approximation to the scaled deviance. Secondly, after a satisfactory representation of the effects of the household variables was found, the area variables were added into the model and the hypotheses concerning the effect of the contextual variables as well as the interaction between the contextual and the household variables were tested. The phases of the model building are summarized in Appendix 1 (p. 27).

\section{Preliminary results on the influence of the household variables}

Of all the households included in the material, 7.9 percent moved during 1981 . Figure 1 shows how the probability of moving depends on each of the explanatory variables. The directions of all the relationships are in accordance with the hypotheses presented above.

a) The older the head of household is, the lower is the probability of moving. The probability of moving for households with 25-29-year-old heads is 3.9 -fold compared with that of households in which the head is $55-59$ years old.

b) Households with children under 7 years old have a 2.1 -fold probability of moving compared to households with older children.

c) Households living densely have a 2.1 -fold probability of moving compared to less densely living households.

d) High-income households have a higher probability of moving than low-income households, but the difference is small ( 21 percent).

The relationships presented in Figure 1 do not correctly show the influence of each of the household variables, since these variables correlate strongly with each other. For example, household type, household income and housing density depend strongly on the age of the household head, and the percentage of households living densely is much higher in the low-income class than in the high-income class (see Figure 2, p. 20).

To find out the effect of each of the independent variables when the influence of the other three variables is adjusted for, a logistic model was fitted. This model included all the main effects of the four variables but ignored possible interactions between them. An attempt was made to simplify the model by assuming a linear trend (on a logistic scale) according to age. However, it was not accepted as it would have led to a considerable loss of fit.

The results of this step are summarized in Table 1, p. 21. Each of the four variables has a statistically significant effect on the probability of moving. The adjusted differences between the categories of the explanatory variables are measured by odds ratios which are defined as

$$
\mathrm{OR}=\frac{\mathrm{p}_{\mathrm{i}} /\left(1-\mathrm{p}_{\mathrm{i}}\right)}{\mathrm{p}_{0} /\left(1-\mathrm{p}_{0}\right)}
$$

where $\mathrm{p}_{0}=$ the probability of moving in the first category of an explanatory variable

and

$\mathrm{p}_{\mathrm{i}}=$ the probability of moving in the $\mathrm{i}_{\text {th }}$ category of an explanatory variable

Table 1 presents for comparison also the odds ratios corresponding to the unadjusted probabilities presented in Figure 1. 
F i g u r e 1. Percentage of households moving during 1981 according to the age of the household head, household type, housing density, household income, the income level of the area and the type of the area.

I. Household variables

1. Age of the head of the household

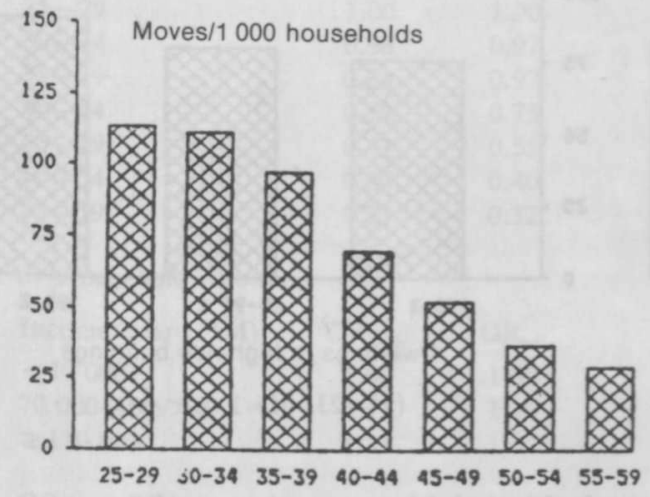

Age of the head of the household

$\left(\chi^{2}=886, \mathrm{df}=6, \mathrm{p}<.001\right)$

3. Housing density

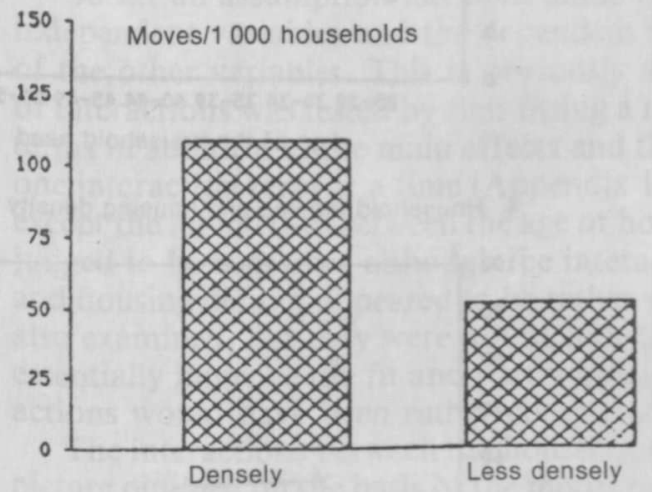

Housing density

$\left(\chi^{2}=713, \mathrm{df}=1, \mathrm{p}<.001\right)$
2. Household type

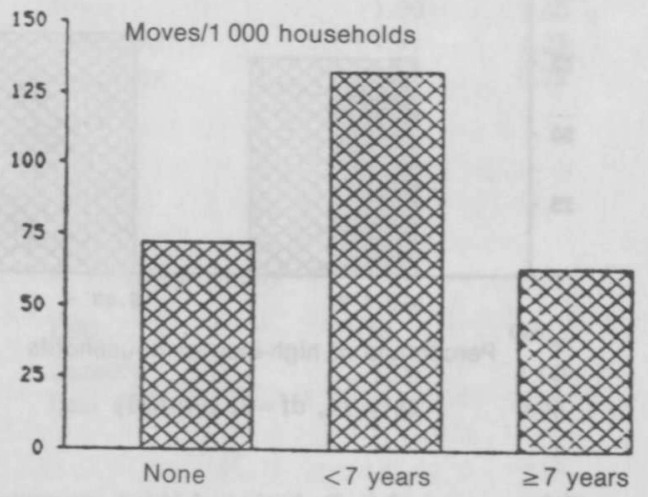

Household type (age of children)

$\left(\chi^{2}=506, \mathrm{df}=2, \mathrm{p}<.001\right)$

4. Household income

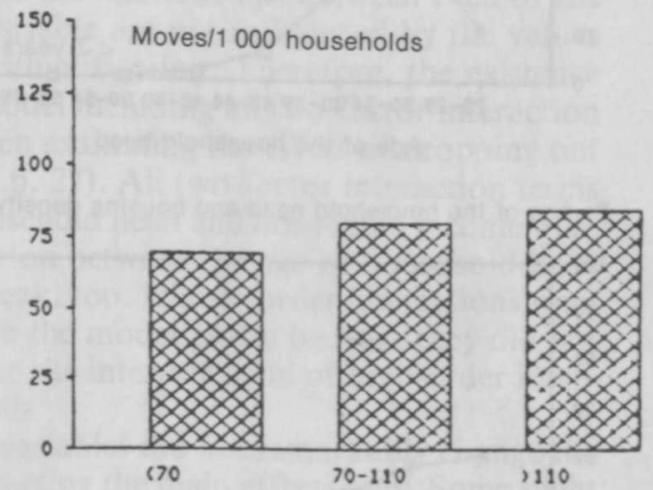

Household income (thousands FIM/year)

$\left(\chi^{2}=25, \mathrm{df}=2, \mathrm{p}<.001\right)$ 


\section{Contextual variables}

1. Income level of the area

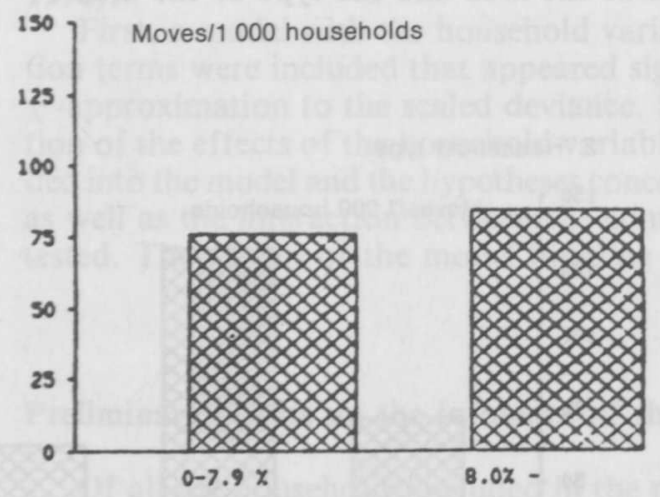

Percentage of high-income households

$$
\left(\chi^{2}=14, \mathrm{df}=1, \mathrm{p}<.001\right)
$$

\section{Area type}

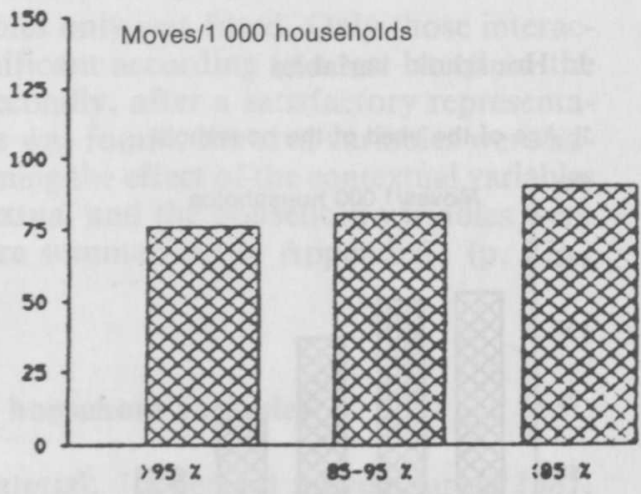

Dwellings in high-rise buildings $\left(\chi^{2}=23, \mathrm{df}=2, \mathrm{p}<.001\right)$

F i g u r e 2. Relationships between household variables: some examples.

1. Age of the household head and household type

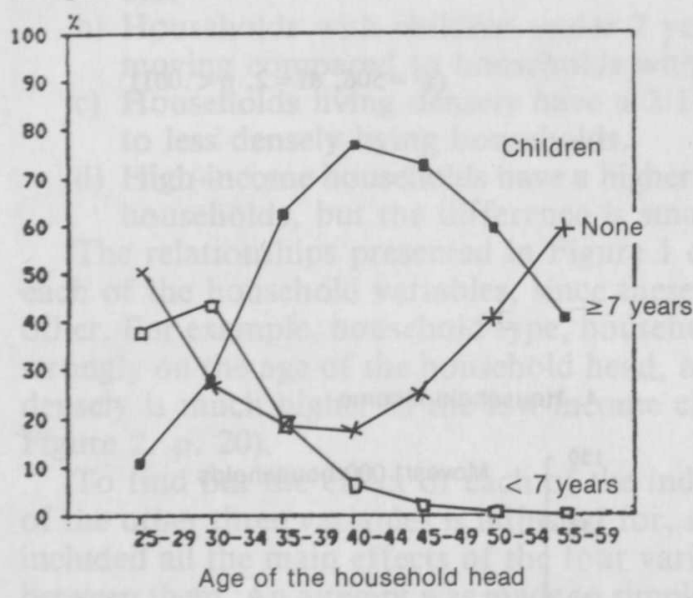

3. Age of the household head and housing density

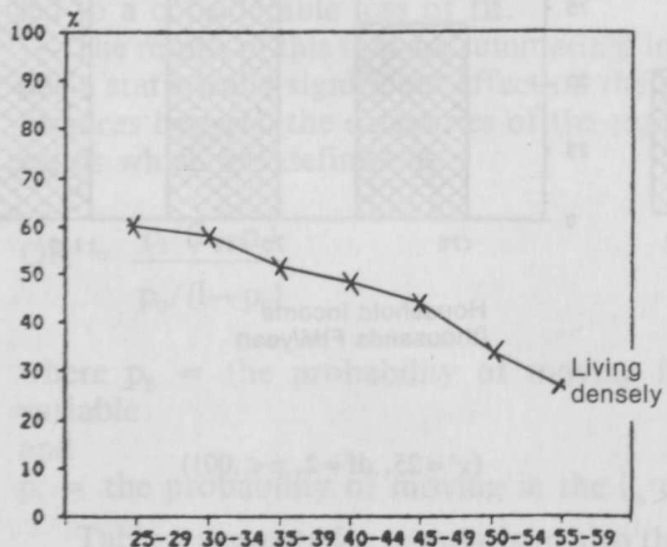

Age of the household head
2. Age of the household head and household income

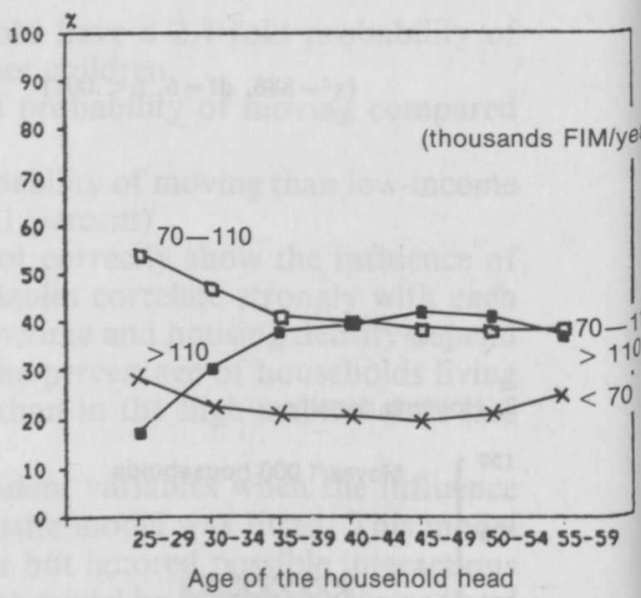

4. Household income and housing density

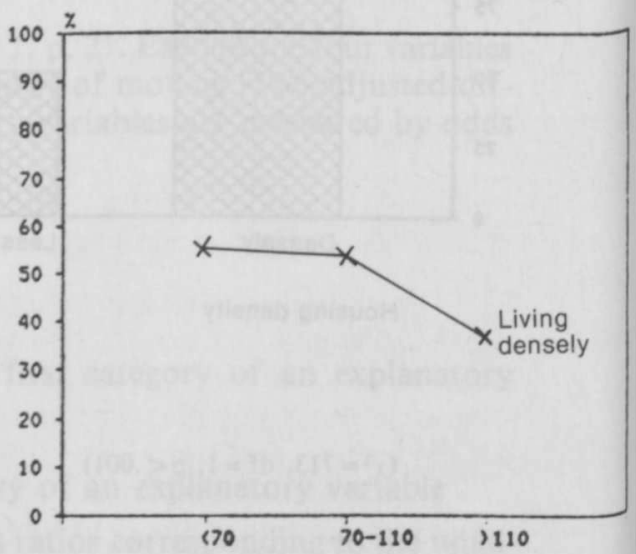

Household income (thousands FIM/year) 
$\mathrm{T}$ a b l e 1. The influence of the household variables on the probability of moving (crude and adjusted odds ratios).

\section{Age of the household head}

Age

$25-29$

$30-34$

$35-39$

$40-44$

$45-49$

$50-54$

$55-59$

$\begin{array}{cc}\mathrm{OR}_{\text {crude }} & \mathrm{OR}_{\text {adj }} \\ & \\ 1.00 & 1.00 \\ 0.98 & 0.97 \\ 0.84 & 0.97 \\ 0.59 & 0.75 \\ 0.43 & 0.55 \\ 0.30 & 0.40 \\ 0.23 & 0.32\end{array}$

\section{Household income}

$\begin{array}{lcc}\text { Income/year (FIM) } & \mathrm{OR}_{\text {crude }} & \mathrm{OR}_{\text {adj }} \\ <70000 & 1.00 & 1.00 \\ 70000-109999 & 1.15 & 1.14 \\ \geq 110000 & 1.23 & 1.57\end{array}$

\section{Household type (age of children)}

$\begin{array}{lll}\begin{array}{l}\text { Household } \\ \text { type }\end{array} & \mathrm{OR}_{\text {crude }} & \mathrm{OR}_{\text {adj }} \\ \text { None } & 1.00 & 1.00 \\ <7 \text { years } & 1.97 & 1.25 \\ \geq 7 \text { years } & 0.87 & 0.78\end{array}$

\section{Housing density}

$\begin{array}{lcc}\text { Density } & \mathrm{OR}_{\text {crude }} & \mathrm{OR}_{\text {adj }} \\ \text { Densely } & 1.00 & 1.00 \\ \text { Less densely } & 0.44 & 0.48\end{array}$

$\mathrm{OR}_{\text {crude }}$ : $O R^{\prime}$ 's according to the model in which the respective variable is the only explanatory variable

$\mathrm{OR}_{\text {adj: }}$ : OR's according to the model including the main effects of all the household variables

When the influence of the other three household variables was adjusted for, the differences between household types and between age categories were diminished because of the strong interdependence between these two variables. On the contrary, adjusting age, household type, and housing density increased the differences between the income categories as households in the highest income group are older and live less densely, which would in general imply a relatively low probability of moving. The odds ratio between the housing density categories remained almost the same after the adjustment for the other factors. According to the statistical criteria, housing density was the most important single explanatory factor among the household variables when the effect of the other three factors was controlled.

So far an assumption has been made that the relationships between each of the independent variables and the dependent variable are not influenced by the values of the other variables. This is obviously a simplification. Therefore, the existence of interactions was tested by first fitting a model including all two-factor interaction terms in addition to the main effects and then examining the effect of dropping out one interaction term at a time (Appendix 1, p. 27). All two-factor interaction terms except the interaction between the age of household head and household income were judged to be necessary although the interaction between the age of household head and housing density appeared to be rather weak, too. Higher-order interactions were also examined, but they were not included in the model partly because they did not essentially improve the fit and partly because the interpretation of high-order interactions would have been rather complicated.

The interactions between the household variables did not remarkably change the picture outlined on the basis of the model including the main effects only. Some slight modifications were introduced, however:

(1) The existence of children in the family as well as their age has some effects on the shape of the age pattern. Firstly, the probability of moving remains on a relatively high level up to the age of 45 years among households with small children. Secondly, if at least one of the children is school-aged, the peak probability of moving does not occur in the youngest age group but rather at 30-39 years of age. (The increase of the probability of moving in the oldest age category among households with small children results probably from the fact that the number of households in this group is very small.) 
(2) The effect of housing density is affected by the income and the type of household as well as to a minor extent, by the age of the household head. On the contrary to what might have been anticipated, the effect of living densely does not seem to be accentuated with increasing income. The odds ratio for those living densely as compared to those living less densely was highest in the middle income group whereas it was almost similar in the lowest and in the highest income groups. This may suggest that »living densely» has a different bearing in different income categories.

The relative odds of moving among households living densely compared to those living less densely is highest in the case of families with pre-school-age children and lowest among families with at least one child of seven years of age or older. This result emphasizes the stability of households with school-aged children. The conclusion is further confirmed by noting that the effect of the increase of household income is smaller in this household type than among families of other types.

As was noted above, the interaction between the age of the household head and housing density was rather weak. The only remarkable exception to the general pattern occurs in the age category 50-54 years, where living densely does not increase the probability of moving as clearly as in the other age groups. There seems to be no obvious explanation to this observation.

(3) As was shown earlier, high-income households have a somewhat higher probability of moving than low-income households. The effect is strongest among households without children. Among households with pre-school-age children, the influence of income is somewhat weaker and the mobility of households with schoolage or older children is influenced least by the income of the household.

The final household model was not, however, sufficient to explain all the variance in the data although the normalized residuals were, in general, rather small.

\section{„Final» model: Results on the simultaneous influence of household and area variables}

One of the purposes of this study was to find out whether certain characteristics of residential areas influence the probability of moving. The empirical percentages of households moving according to the income level of the area and the type of physical environment are shown in Figure 1. The differences between area types are small but statistically significant. The probability of moving for households living in low-income areas is smaller than for households in high-income areas. In the densely built central areas the probability of moving is lower than in the less densely built suburbs.

The differences between area types may be caused by differences in the composition of the population. For example, it is tautologically obvious that the percentage of high-income households is higher in high-income areas than in low-income areas. It is also known that the percentage of old and, consequently, less mobile households is greater in the central city than in the suburbs. It turned out, however, that the area variables sustained their statistical significance when they were added to the household level model constructed in the previous section. Therefore a "final» model including both the household level variables and the area variables was constructed.

The strategy applied in constructing the final model was similar to the one followed in the case of the household model; firstly, all two-factor interactions between the area variables and the household variables as well as the interaction between the two area variables were added to the current model (i.e. the household model plus the main effects of the area variables) and, secondly, all non-significant interactions were omitted. There remained two interaction terms which were significant at the 5 percent level, namely the interaction between the income level of the area and the household income and the interaction between the type of physical environment and the housing density. The interaction between the type of physical environment and 
the household type was also included in the final model although it narrowly failed to reach the 5 percent significance which was applied as the criterion.

However, even the model with all two-factor interactions between the area variables and the household variables did not fit the data adequately, which suggested the need for some higher-order interactions. In spite of this fact the model described above was chosen as a basis for the interpretation because there were no obvious hypotheses about higher-order interactions, and a systematic search for a better model would have been a very heavy task computationally. In addition, the lack of fit of the model is partly due to the extensiveness of the data.

The inclusion of the two area variables or the three new interaction terms does not change the previous conclusion about the general importance of each of the household level variables. As for the contextual variables, according to the "ffinal» model the probability of moving was in general highest in the densely built areas and in the high-income areas, the latter result being opposite to the original assumption. weak:

The interactions between the household factors and the contextual factors were

(1) The interactive effect of the household income and the respective area variable is slightly in accordance with the hypothesis: the increase in the probability of moving with increasing income is to some extent higher in the low-income areas than in the high-income areas. However, even among households in the highest income category the probability of moving is greatest in the high-income areas.

(2) According to the hypothesis, the probability of moving for households with pre-school-age children should be relatively higher in the central city and other residential areas dominated by high-rise buildings than in the less densely built areas. The differences between area types are, however, small and inconsistent.

(3) No a priori hypothesis was made about the interaction between area type and housing density. The interaction term suggests that living densely increases the odds for moving more in high-rise areas than in areas built less densely. On the other hand, households living less densely were less likely to move in high-rise areas than in the less densely built areas. This might suggest that the densely built central areas are not considered undesirable as such if only the apartment is adequate.

The parameter estimates of the final model as well as the standard errors of the estimates are presented in Appendix 2, p. 28. To give illustrative examples of the interactions, Figure 3, p. 24 depicts for each interacting pair of factors the estimated probability of moving in every combination of their levels, when the other four explanatory variables are fixed on their first level.

According to the final model, the lowest expected probability of moving $(1.2 \%)$ occurs among medium-income households in which the head is 55-59 years old, all children are above seven years old and housing density is low and who are living in a low-income area with more than $95 \%$ of dwellings in high-rise buildings. On the other hand, according to the model the highest probability of moving $(25 \%)$ is to be expected among high-income households with young children and the household head aged $25-29$ years who are living densely in a high-income central area. (Only non-empty cells of the data were considered in these examples.)

\section{Discussion}

The results on the main effects of the household variables on the probabilities of moving of households were in accordance with the hypotheses presented. Each of the four variables had a statistically significant effect on the probability of moving even when the effects of the other variables were adjusted for. The most important variables were the housing density and the age of the household head. This fits well with the general view that residential mobility is mainly connected to the adjustment 
F i g u r e 3. The estimated probability of moving in the categories of the interactive pairs of variables (the final model) ${ }^{1}$.

1. Age of the household head and household type

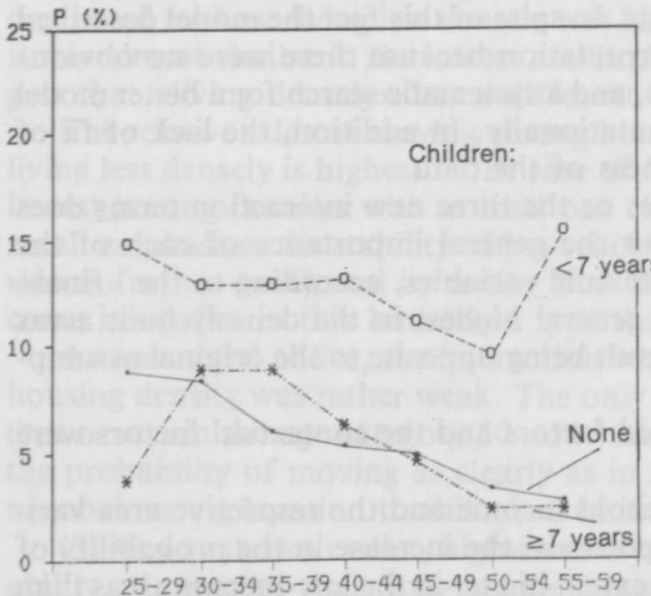

Age of the household head

3. Housing density and household type

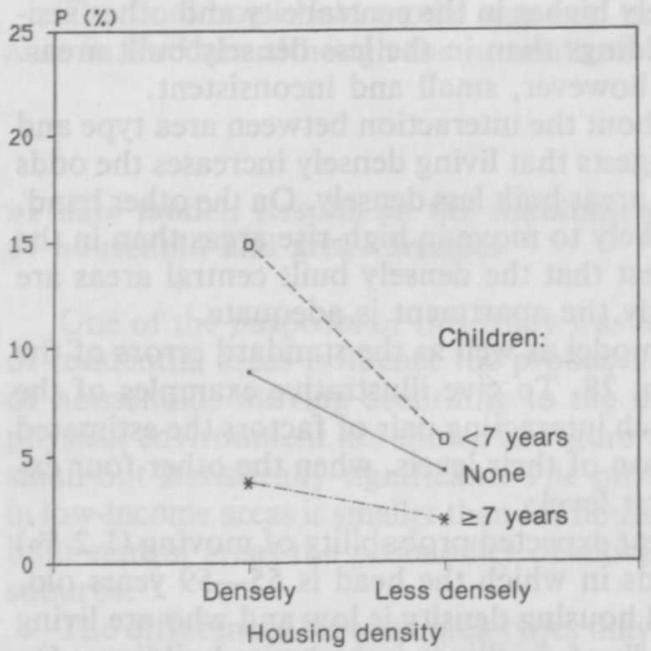

5. Household income and household type

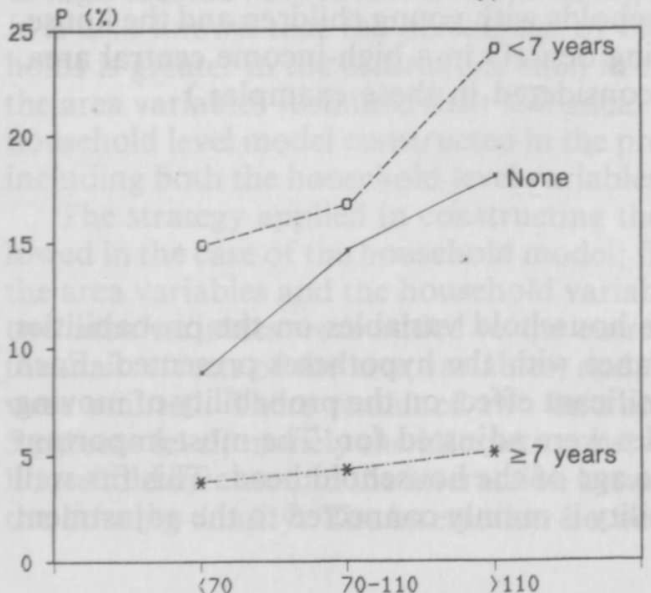

Household income (1000 FIM/year)
2. Housing density and household income

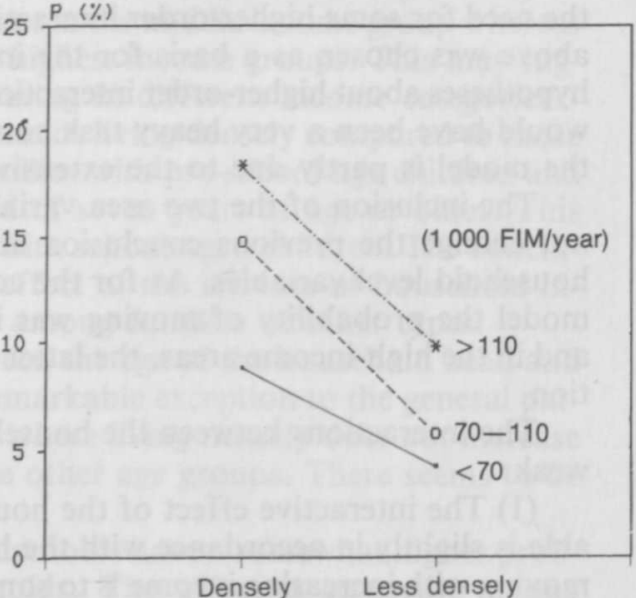

Housing density

4. Housing density and age of the household head

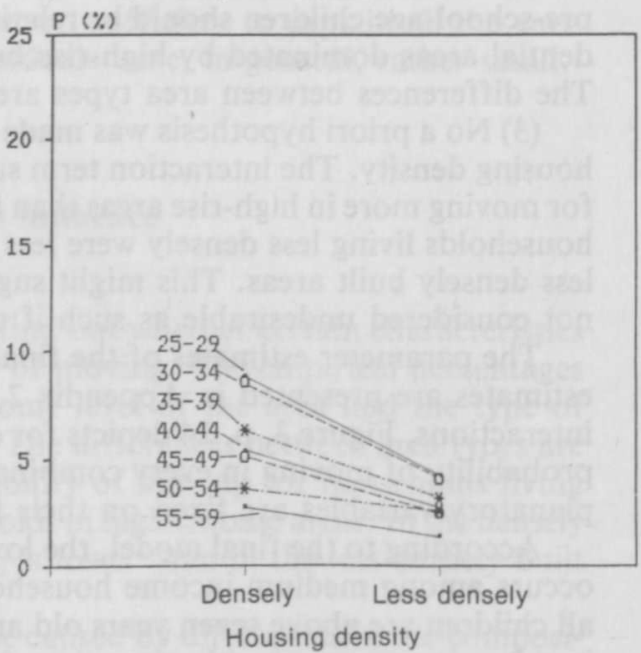

6. Household income and the income level of the area

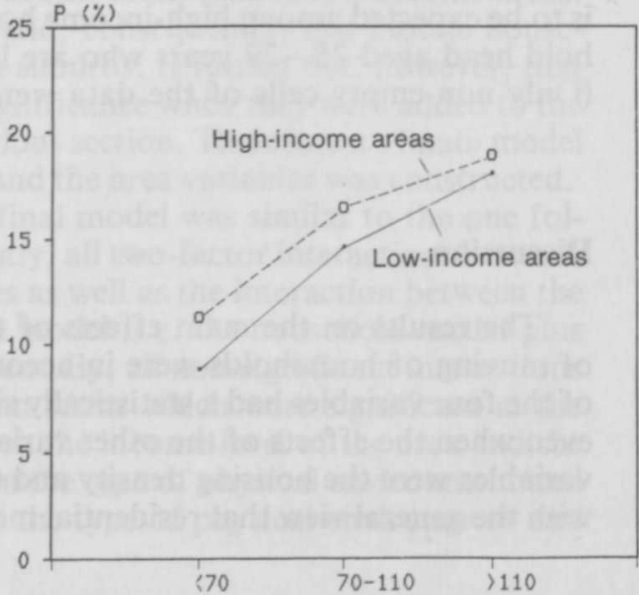

Household income (1 000 FIM/year) 
7. Household type and area type

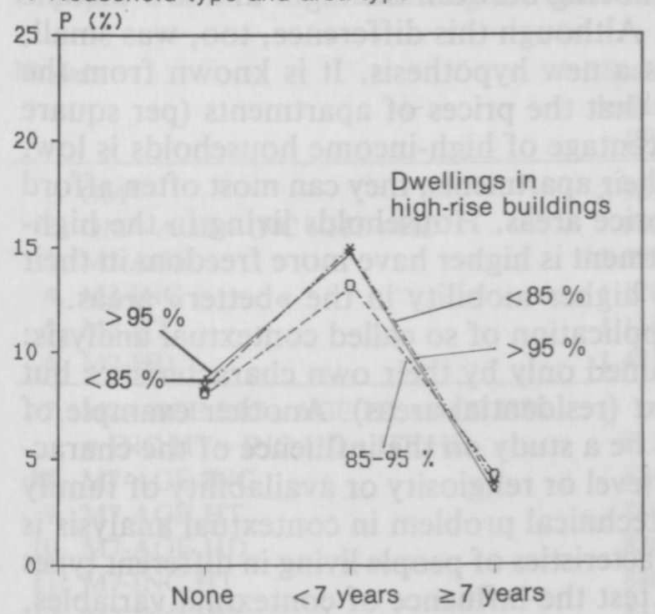

Household type (age of children)
8. Housing density and area type

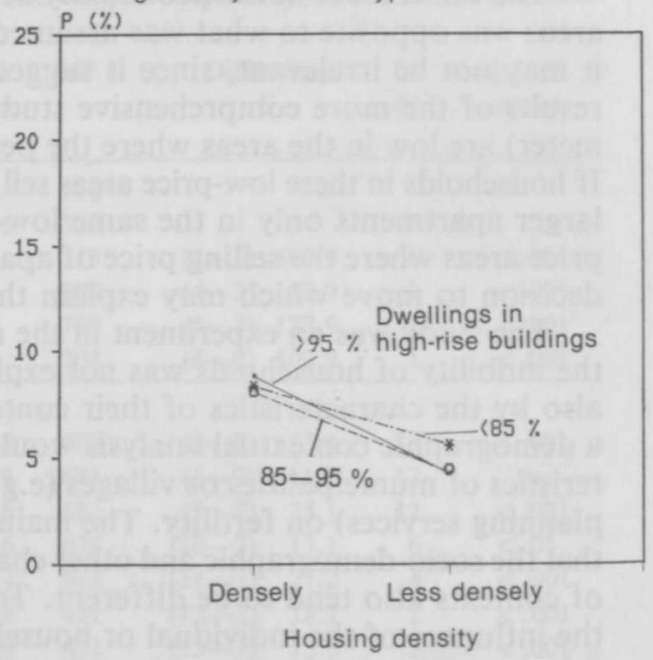

${ }^{1}$ In these examples the other four explanatory variables are fixed on their first level, i.e.

- age of the household head $=25-29$ years

- household type $=$ no children

- housing density $=$ living densely

- household income $=<70000 \mathrm{FIM} /$ year

- income level of the area $=$ low income

- area type $=>95 \%$ of the dwellings in high-rise buildings

of families to changing housing needs. The high mobility of households with preschool-age children is also connected to this adjustment process. The lower mobility of households with school-age children is probably mostly due to the reluctance to change schools.

The interactive effects of the above-mentioned variables are, in general, not very strong. It seems, however, that pre-school-age children in the family keep the probability of moving rather high even for households where the age of the household head is relatively high whereas school-age children decrease the mobility even though there would be a need for a larger dwelling and though the income level of the household would allow for it.

High household income was assumed to be connected with better opportunities of moving and, thus, higher mobility. Such a relationship was also found although the differences between income classes were small. The association was strengthened when the effect of the other three household factors was adjusted for. There was also an interactive effect of income and housing density but it was rather surprising and hard to interpret since the mobility of densely living households in the highest income group was not exceptionally high. There seems to be no obvious explanation to this unexpected result.

The study attempted to show the possible influence of area characteristics on the mobility of households. The variables chosen to classify the areas into types of environments may not have been the best possible and many important aspects of areas (e.g. supply of daycare services and new dwellings) were not considered. It seems clear, however, that the six types of areas distinguished here differ strongly from each other. Therefore, if the characteristics of areas are at all relevant to the rate of residential mobility, differences among the area types should have been found. According to the results there were, indeed, statistically significant differences, but they were very small if compared with the differences between the classes of household variables. The main conclusion thus is that household characteristics are much more important determinants of residential mobility than area characteristics. 
The differences in the probability of moving between the high- and low-income areas was opposite to what was assumed. Although this difference, too, was small, it may not be irrelevant, since it suggests a new hypothesis. It is known from the results of the more comprehensive study that the prices of apartments (per square meter) are low in the areas where the percentage of high-income households is low. If households in these low-price areas sell their apartments, they can most often afford larger apartments only in the same low-price areas. Households living in the highprice areas where the selling price of apartment is higher have more freedom in their decision to move which may explain the higher mobility in the »better» areas.

The study was an experiment in the application of so called contextual analysis: the mobility of households was not explained only by their own characteristics but also by the characteristics of their context (residential areas). Another example of a demographic contextual analysis would be a study on the influence of the characteristics of municipalities or villages (e.g. level or religiosity or availability of family planning services) on fertility. The main technical problem in contextual analysis is that the socio-demographic and other characteristics of people living in different types of contexts also tend to be different. To test the influence of contextual variables, the influence of the individual or household level variables has to be controlled. In this study this was done by using a logistic model including both household and area level independent variables. This procedure seemed to work satisfactorily and the absence of clear contextual effects was obviously not caused by the techniques of analysis.

\section{References}

Baker, R. J.; and Nelder, J. A. (1978). The GLIM system. Release 3. Manual. The Royal Statistical Society, Numerical Algorithms Group, Oxford.

Brown, L. A.; and Moore, E. G. (1970). The intra-urban migration process: A perspective. Geografiska Annaler 52 B: $1-13$.

Rossi, Peter H. (1980). Why families move. Glencoe Ill (1955).

Summa, Hilkka (1984). Muuttoliike ja asunnonvaihdot päăkaupunkiseudulla. Kirjallisuuskatsaus. Pääkaupunkiseudun julkaisusarja B 1984: 3.

Valkonen, T.; Martelin, T.; and Summa, H. (1984). Muuttoliike ja asunnonvaihdot pääkaupunkiseudulla. (Swedish summary: Om flyttningen och bostadsbyten i huvudstadsregionen. Sammandrag och slutsatser). Pääkaupunkiseudun julkaisusarja B 1984: 1. Helsinki. 
A p p e n d i x 1. Modelling the odds for moving: a summary of the main phases.

\begin{tabular}{|c|c|c|c|c|c|c|}
\hline odel & $\begin{array}{c}\text { Scaled } \\
\text { deviance } \\
\text { (S) }\end{array}$ & $\mathrm{df}$ & Di & $e$ & in & \\
\hline $\begin{array}{l}\text { 1. } \mathrm{GM}^{1} \\
\text { 2. } \mathrm{GM}+\mathrm{AGE}+\mathrm{INC}+\mathrm{HT}+\mathrm{HD} \\
\text { 3. } \mathrm{M} 2-\mathrm{AGE} \\
\text { 4. } \mathrm{M} 2-\mathrm{INC} \\
\text { 5. } \mathrm{M} 2-\mathrm{HT} \\
\text { 6. M2-HD }\end{array}$ & $\begin{array}{ll}2 & 588 \\
987.1 \\
1 & 398 \\
1 & 120 \\
1 & 115 \\
1 & 491 \\
\end{array}$ & $\begin{array}{l}718^{2} \\
707 \\
713 \\
709 \\
709 \\
708 \\
\end{array}$ & $\begin{array}{ll}(3-2) & 4 \\
(4-2) & 1 \\
(5-2) & 1 \\
(6-2) & 5 \\
\end{array}$ & $\begin{array}{l}410.9 \\
132.9 \\
127.9 \\
503.9 \\
\end{array}$ & $\begin{array}{l}6 \\
2 \\
2 \\
1 \\
\end{array}$ & $\begin{array}{l}<.001 \\
<.001 \\
<.001 \\
<.001 \\
\end{array}$ \\
\hline $\begin{array}{l}\text { 7. M2+AGE.INC+AGE.HT+AGE.HD } \\
\text { + INC.HT + INC.HD + HT.HD } \\
\text { *8. M7-AGE.INC } \\
\text { 9. M7-AGE.HT } \\
\text { 10. M7-AGE.HD } \\
\text { 11. M7-INC.HT } \\
\text { 12. M7-INC.HD } \\
\text { 13. M7-HT.HD } \\
\text { 14. AGE*INC*HT*HD (all two-, three-, } \\
\text { and four-factor interactions) }\end{array}$ & $\begin{array}{l}813.5 \\
824.8 \\
888.6 \\
826.6 \\
840.7 \\
831.6 \\
829.0\end{array}$ & $\begin{array}{l}669 \\
681 \\
681 \\
675 \\
673 \\
671 \\
671\end{array}$ & $\begin{array}{l}(2-7) \\
(8-7) \\
(9-7) \\
(10-7) \\
(11-7) \\
(12-7) \\
(13-7) \\
(14-8) 1\end{array}$ & $\begin{array}{r}173.6 \\
11.3 \\
75.1 \\
13.1 \\
27.2 \\
18.1 \\
15.5 \\
108.0\end{array}$ & $\begin{array}{r}38 \\
12 \\
12 \\
6 \\
4 \\
2 \\
2\end{array}$ & $\begin{array}{l}<.001 \\
\text { ns } \\
<.001 \\
<.05 \\
<.001 \\
<.001 \\
<.001 \\
\\
<.10)\end{array}$ \\
\hline $\begin{array}{l}\text { 15. } \mathrm{M} 8+\mathrm{AT} \\
\text { 16. } \mathrm{M} 8+\mathrm{IL} \\
\text { 17. } \mathrm{M} 8+\mathrm{IL}+\mathrm{AT}\end{array}$ & & $\begin{array}{l}680 \\
678 \\
\end{array}$ & $\begin{array}{r}(8-15) \\
(8-16) \\
(16-17) \\
\end{array}$ & $\begin{array}{r}14.1 \\
20.9 \\
7.1 \\
\end{array}$ & 2 & $\begin{array}{l}<.001 \\
<.001 \\
<.05\end{array}$ \\
\hline $\begin{array}{l}\text { 18. } \text { M17+AGE.IL+AGE.AT + INC.IL } \\
\text { + INC.AT + HT.IL + HT.AT + HD.IL } \\
\text { +HD.AT + IL.AT } \\
\text { 19. M18-AGE.IL } \\
\text { 20. M18-AGE.AT } \\
\text { 21. M18-INC.IL } \\
\text { 22. M18-INC.AT } \\
\text { 23. M18-HT.IL } \\
\text { 24. M18-HT.AT } \\
\text { 25. M18-HD.IL } \\
\text { 26. M18-HD.AT } \\
\text { 27. M18-IL.AT } \\
\text { 28. M17+INC.IL + HT.AT + HD.AT }\end{array}$ & $\begin{array}{l}720.8 \\
728.9 \\
738.0 \\
726.9 \\
727.3 \\
723.9 \\
730.1 \\
720.9 \\
727.0 \\
725.3 \\
763.4\end{array}$ & $\begin{array}{l}643 \\
649 \\
655 \\
645 \\
647 \\
645 \\
647 \\
644 \\
645 \\
645 \\
670\end{array}$ & $\begin{array}{l}(17-18) \\
(19-18) \\
(20-18) \\
(21-18) \\
(22-18) \\
(23-18) \\
(24-18) \\
(25-18) \\
(26-18) \\
(27-18)\end{array}$ & $\begin{array}{r}76.0 \\
8.1 \\
17.2 \\
6.1 \\
6.5 \\
3.1 \\
9.3 \\
0.1 \\
6.2 \\
4.5\end{array}$ & $\begin{array}{r}35 \\
6 \\
12 \\
2 \\
4 \\
2 \\
4 \\
1 \\
2 \\
2\end{array}$ & $\begin{array}{c}<.001 \\
\text { ns } \\
\text { ns } \\
<.05 \\
\text { ns } \\
\text { ns } \\
(<.10) \\
\text { ns } \\
<.05 \\
\text { ns }\end{array}$ \\
\hline
\end{tabular}

1 Abbreviations: $\mathrm{GM}=$ general mean

$$
\begin{aligned}
\text { AGE } & =\text { age of the household head } \\
\text { INC } & =\text { household income } \\
\text { HT } & =\text { household type } \\
\text { HD } & =\text { housing density } \\
\text { AT } & =\text { area type } \\
\text { IL } & =\text { income level of area }
\end{aligned}
$$

${ }^{2}$ The maximum number of units (cells) would have been $7 \times 3 \times 3 \times 2 \times 3 \times 2=756$ but 37 empty cells were omitted. 


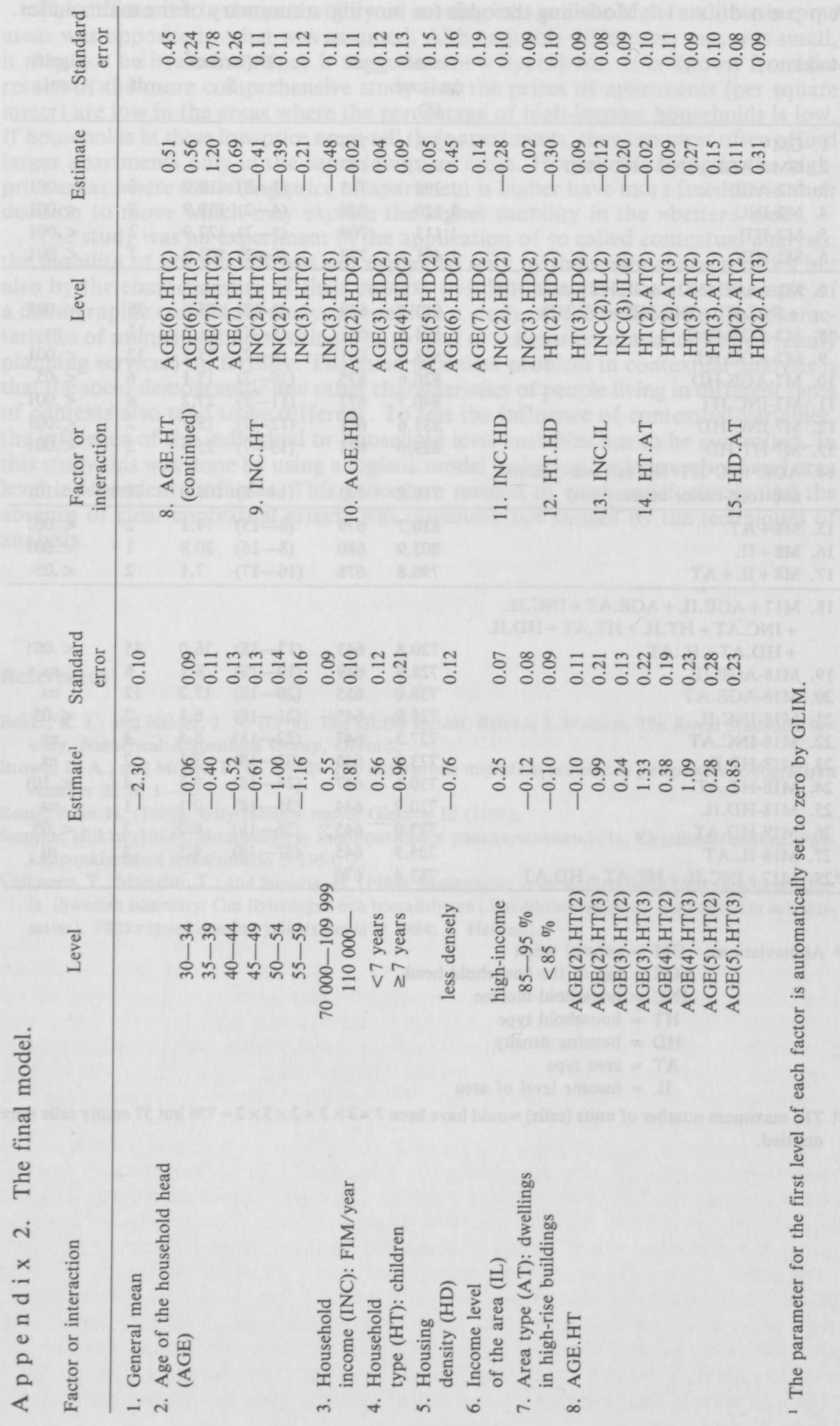

